\title{
Experimental investigation on the filtration of a novel composite plastic blind drainage on expansive soil slope
}

\author{
Guo Cheng Wen ${ }^{1,2,}{ }^{*}$, Lei Zheng ${ }^{2}$, Qiong $\mathrm{Chen}^{3}$, Jun Yan ${ }^{2,3}$, and Hua Wei ${ }^{4}$ \\ ${ }^{1}$ College of Water Conservancy and Hydropower, Hohai University, Nanjing 210098, China \\ ${ }^{2}$ Hydraulic Engineering Department, Nanjing Hydraulic Research Institute, Nanjing 210029, China \\ ${ }^{3}$ Anhui R \& D Hi-Tech Engineering Co., Ltd., Nanjing 210024, China \\ ${ }^{4}$ Materials \& Structural Engineering Department, Nanjing Hydraulic Research Institute, Nanjing 210029, China
}

\begin{abstract}
Extensive clogging occurs to the blind drainage due to the high clay content of the expansive soil slope and the distinctly different grain composition between the matrix and the sand cushion. Thus, a novel composite plastic blind drainage was designed and its seepage performance was explored by laboratory filter test. Compared to the conventional system, adopting the new plastic blind drainage significantly reduced the demand of sand and gravel for field application. The results from the laboratory tests revealed that, the seepage of the drainage system with this novel composite plastic blind drainage functioned steadily in the long-term.
\end{abstract}

\section{Introduction}

Expansive soil has the characteristics of high volume instability, high porosity and sensitivity to humidity change[1-2]. Thus, the structural strength of the expansive-soil slope degrades significantly when subjected to several drying-wetting cycles, and the reliable drainage is very important for the long-term stability of expansive soil slope.

After the excavation of the expansive soil slope, Concrete bricks, cement-stabilized soil blocks and geotextiles are normally applied to resist the rainfall seepage3. Meanwhile, drainage systems should be construct within the slope to drain the underground water, in order to prevent the slope instability induced by the seepage from the backward slope. The drainage systems are commonly-seen in drainage hole, relief well and blind drainage. The former two are the convergence points in the 3-D seepage fields of the slope, the proper installation is complicated and the geological conditions and engineering operation conditions should be fully considered. In contrast to the drainage hole and the relief well, the blind drainage is a linear structure, which is convenient for installation and is widely used in practices. However, one major problem involving the conventional blind drainage is the significant clogging, and the plastic blind drainage was so designed. The plastic blind drainage consists of the plastic core and the geotextile filtration film cover, which is of variety types, high drainage capacity and high bearing capacity4. However, due to the possible blockage caused by the clay part of the expansive soil, in terms of the slope of the expansive soil, the conventional plastic blind drainage may cause drainage failure.
To address the issue above, a novel composite plastic blind drainage was used and the laboratory filtration test was performed to test its capabilities of drainage and anti-clogging, as well as the feasibility in the practical application.

\section{Materials}

\subsection{Novel composite plastic blind drainage}

The novel composite plastic blind drainage (NBD) was supplied by the Anhui R \& D Hi-Tech Engineering Co., Ltd., and consists of a drain pipe, a geotextile and a plastic filter body. The cross section diagram is shown in Figure 1, and the inner diameter is $160 \mathrm{~mm}$.

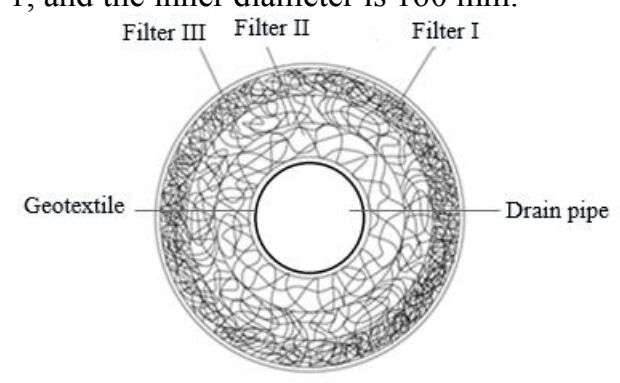

Fig. 1. Cross section diagram of the NBD

This study mainly focused on the composite filter body which composed of plastic filter and geotextile in NBD. Three types of the geotextiles were used in this paper with the basic properties summarized in Table 1.

\footnotetext{
* Corresponding author: wgcsometime@163.com
} 
Table 1. Basic properties of the geotextiles

\begin{tabular}{ccccc}
\hline & Thickness & $\begin{array}{l}\text { Equivalent } \\
\text { opening size }\end{array}$ & $\begin{array}{l}\text { Hydraulic } \\
\text { conductivity }\end{array}$ & $\begin{array}{l}\text { Mass per } \\
\text { unit area }\end{array}$ \\
\cline { 2 - 5 } & $\mathrm{mm}$ & $\mathrm{mm}$ & $\mathrm{cm} / \mathrm{s}$ & $\mathrm{g} / \mathrm{m}^{2}$ \\
\hline filament spunbonded & 2.8 & 0.237 & 0.157 & 203 \\
staple fibers A & 2.9 & 0.135 & 0.103 & 201 \\
staple fibers B & 3.4 & 0.087 & 0.090 & 406 \\
\hline
\end{tabular}

In addition, the plastic filter body is the major body of the blind drainage and is composed by 3 filtration layers with different pore sizes arranged in the order of increasing pore size from outside to inside. The average porosity of the filter body is $79.7 \%$ and the average equivalent opening size is $3.28 \mathrm{~mm}$.

\subsection{Expansive soil}

The expansive soil was sampled from the Jianghuai communication section of the Water Diversion Project from Yangtze River to Huaihe River. The basic properties and the particle size distribution were controlled to the Standard for Soil Test Method (GB/T 50123-2019), and are shown in Table 2 and Figure 2, respectively. The test results reveal that the soil is classified as clay high plastic soil (CHS), and the $\mathrm{d}_{85}=0.25 \mathrm{~mm}, \mathrm{~d}_{15}=0.008 \mathrm{~mm}$, the non-uniformity coefficient is 68.57 .

Table 2. Basic properties of the soil

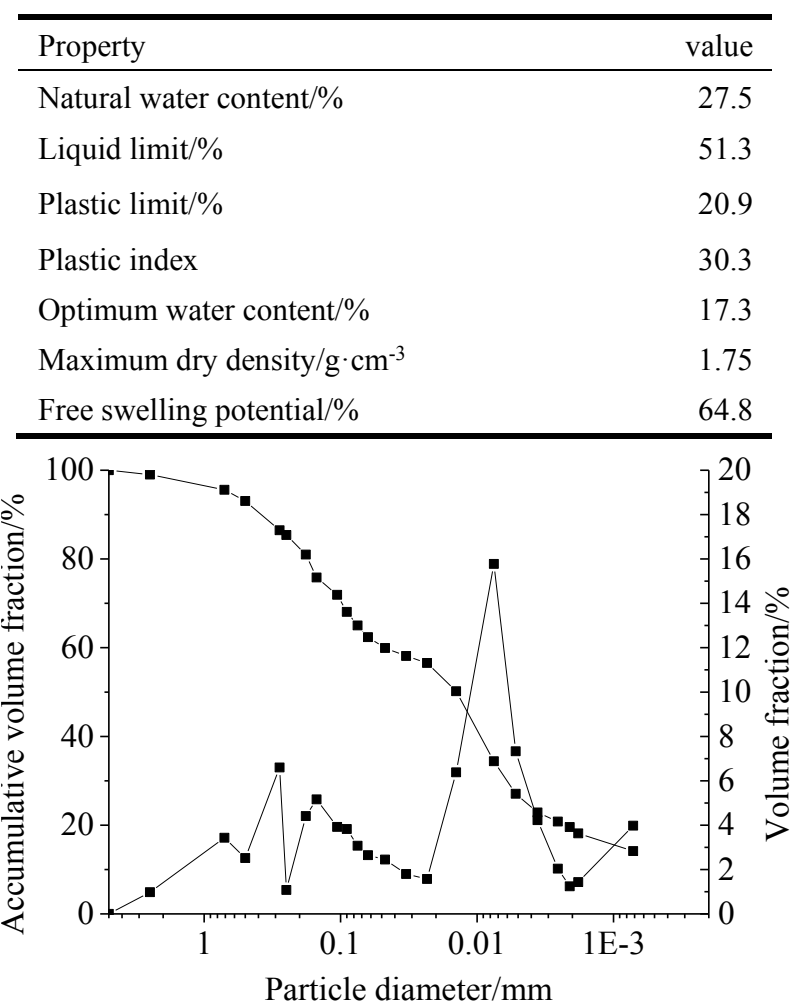

Fig. 2. Particle size distribution curve

\section{Methodology}

The filtration test device is shown in Figure 3.

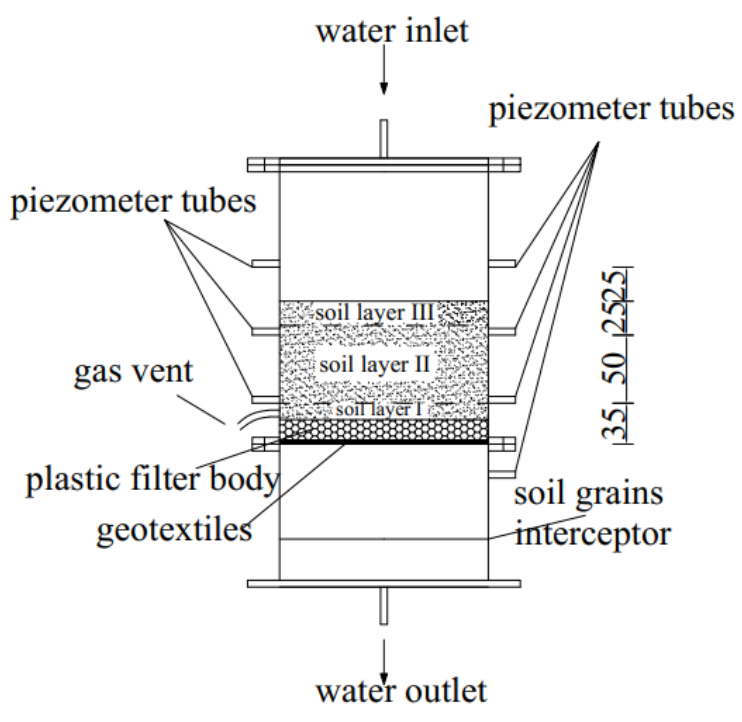

Fig. 3. Diagram of filtration test device

The main structure of the equipment is an organic glass cylinder with an inner diameter of $15.3 \mathrm{~cm}$ and symmetrical piezometer tubes were arranged at $35 \mathrm{~mm}$, $85 \mathrm{~mm}$ and $135 \mathrm{~mm}$ away from the geotextile sample. The soil layers above the geotextile $(0-35 \mathrm{~mm}, 35-85$ $\mathrm{mm}, 85-110 \mathrm{~mm}$ ) were denoted as soil layer I, soil layer II, and soil layer III. The constant seepage method was applied to the filtration test, and the hydraulic gradients were set to 1 at first and then to 4 to simulate the water head change in the real cases. The plastic filter body was cut from the composite plastic blind drainage and processed into the appropriate size. In the cylinder, a supporting net, a geotextile, the plastic filter and the soil sample were set successively from the bottom to the top. Soil samples were compacted into the equipment by 3 layers and the height, diameter and the dry density were controlled to $15.3 \mathrm{~cm}, 9 \mathrm{~cm}$ and $1.59 \mathrm{~g} / \mathrm{cm}^{3}$, respectively. The test duration was pre-set to $150 \mathrm{~h}$ and was adjust according to the seepage change of each sample. After the sample installation, water temperature, water head and water drainage were recorded per $0.5-8 \mathrm{~h}$, to calculated the hydraulic conductivity. When the seepage was stable5, the geotextile was removed and immersed into the water for $30-60 \mathrm{~min}$ to precipitate the soil particles. Hereafter, the plastic filter was removed, the bottom soil was collected and oven-dried along with the geotextile. Then, the masses of the geotextile, the silting soil in the plastic filter and the soil passing the geotextile were weighted. Finally, the hydraulic conductivities of the geotextile after the filtration test was tested.

\section{Result Analyses}

4.1 Soil protection performances 
The soil protection performances of different NBDs were first characterized by the hydraulic conductivities of the soil layers, the results of which are summarized in Figure $4 \mathrm{a}-4 \mathrm{c}$.

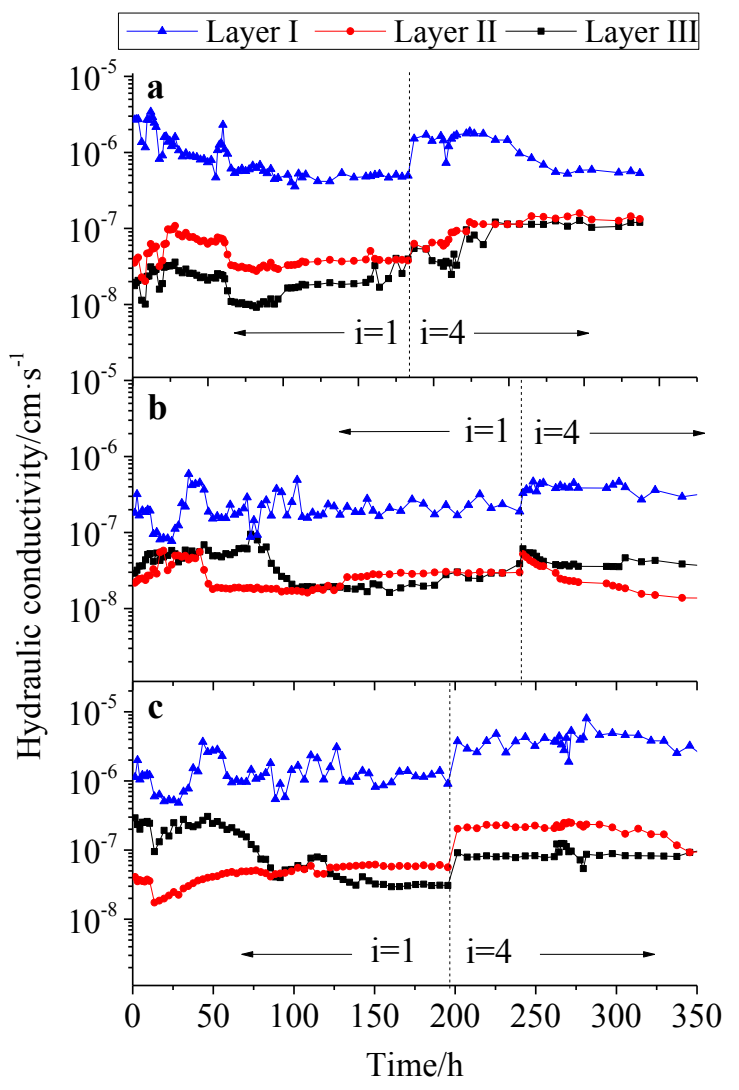

Fig. 4. Hydraulic conductivities against the test time of the soil layers with the NBD with a: filament spunbonded, b: staple fibers A, c: staple fibers B

The results reveal that the hydraulic conductivities of all NBD-soil systems fluctuated greatly at the initial stage with the hydraulic gradient 1 , then gradually stabled, indicating that the soil structures were stable. Meanwhile, the stable time varied with regards to the geotextile types and the beginnings of the stable time were at $\sim 150 \mathrm{~h}$. After the hydraulic gradient reached to 4 , substantial increases occurred to the hydraulic conductivities, indicating that the fine-grained soils were taken away by the water flow. Likewise, the hydraulic conductivities of all systems stabled in the final stage, indicating that the NBD was capable of maintaining the stability of soil structure. In this paper, the average pore sizes of the NBDs were significantly higher than the average particle diameter of the tested soil, and the results are well-consistent with previous studies[6-8].

Hereafter, the soils passed through the NBD systems were collected and weighted. The masses were $0.45 \mathrm{~g}$ for the filament spunbonded, $0.15 \mathrm{~g}$ for the staple fibers A and $0.093 \mathrm{~g}$ for the staple fibers $\mathrm{B}$, indicating that the properties of the geotextiles highly affected the soil protection performances. The major reason for this fact was that the filament spunbonded geotextile has a larger equivalent opening size.

\subsection{Water permeability}

The hydraulic conductivities of the geotextiles before and after the infiltration test were summarized in Table 3.

Table 3. Hydraulic conductivities of the geotextiles before and after the filtration test

\begin{tabular}{cccc}
\hline \multirow{2}{*}{ Name } & Before & After & reduction \\
\cline { 2 - 4 } & $\mathrm{cm} / \mathrm{s}$ & $\mathrm{cm} / \mathrm{s}$ & $\%$ \\
\hline filament spunbonded & 0.157 & 0.073 & 53.5 \\
staple fibers A & 0.13 & 0.092 & 29.2 \\
staple fibers B & 0.090 & 0.058 & 35.5 \\
\hline
\end{tabular}

Table 3 reveals that the highest reduction $53.5 \%$ of the hydraulic conductivity occurred to the filament spunbonded geotextile. Nevertheless, the hydraulic conductivities of the geotextiles after the test were higher than those of the soil layers.

In addition to the soil clogged in the plastic filter body, the masses per unit volume were $0.3 \mathrm{~g} / \mathrm{cm}^{3}, 0.328$ $\mathrm{g} / \mathrm{cm}^{3}$ and $0.338 \mathrm{~g} / \mathrm{cm}^{3}$ for the NBD with the filament spunbonded, the staple fibers A and the staple fibers B, respectively. If the dry density of the silt soil is still 1.59 $\mathrm{g} / \mathrm{cm}^{3}$, the occupied volume fractions by the fine-grained soil in the plastic filter were $18.86 \%, 20.65 \%$ and $24.07 \%$ respectively. Considering the initial porosity $79.7 \%$ of the filter body, the residue pore volume assures the long-term seepage performance of the NBD system.

\subsection{Anti-clogging performance}

The anti-clogging performance characterizes the longterm permeability of the NBD. Thus, the gradient ratio (GR) and the soil mass per unit volume were employed to evaluate the clogging degree with the results summarized in Figure 5 and Table 4, respectively. The GR is the ratio of the hydraulic conductivity of the soil to that of the soil containing the filter.

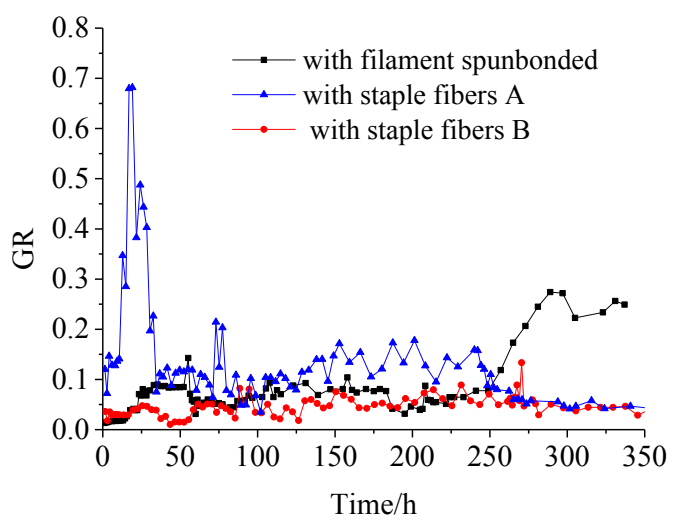

Fig. 5. GR value against the test time with regards to geotextile types

It is evident that the hydraulic conductivity of soil layer II was 1 magnitude smaller than that of soil layer I and was stable in a small range without obvious clogging. 
Table 4. Blocked soil of the geotextiles and the filter body

\begin{tabular}{ccc}
\hline \multirow{2}{*}{ Name } & Geotextile & Filter body \\
\cline { 2 - 3 } & $\mathrm{g} / \mathrm{cm}^{3}$ & $\mathrm{~g} / \mathrm{cm}^{3}$ \\
\hline filament spunbonded & 0.0096 & 0.3 \\
staple fibers A & 0.0114 & 0.328 \\
staple fibers B & 0.0152 & 0.383 \\
\hline
\end{tabular}

Table 4 reveals that the soil masses per unit volume of staple fibers A and B were higher than that of filament spunbonded geotextile. Such fact is due to that the equivalent pore sizes of staple fibers $\mathrm{A}$ and $\mathrm{B}$ were smaller than that of filament spunbonded geotextile. Consequently, soil particles mainly tended to gather on the surface rather than pass into the interior.

In addition, the soil masses per unit volume of the filter bodies were higher than the geotextiles. Two possibilities account for this fact. First, the filter bodies enable filtering and retaining expansive soil, only the soil particles smaller than outermost pore diameter would pass through. Second, the soil particles could be pressed into the filter body during the sample compacting. Notably, the silt soil mass was substantially higher for the NBD system with the staple fibers. It was because that the soil silt more easily in terms of smaller equivalent pore, thus more silt soil would participate onto the filter body.

In terms of the practical cases, the medium coarse sand is backfilled around the plastic blind drainage. Thus, the sand, along with the surrounding soil can be regarded as the discontinuous graded soil. Under the function of seepage, soil particles either gather onto the interface of the sand and the soil or silt within the pores of the sand structure, which highly reduces the drainage performance. While in this paper, the NBD with larger pore size did not lead to the soil structure damage, and effectively prevented the clogging. Therefore, the NBD application ensures the long-term effectiveness of drainage system in the expansive soil slope under the condition of replacing sand and gravel partially.

\section{Conclusions}

This paper investigated the possible application of a novel composite plastic blind drainage (NBD) on expansive soil slope by laboratory filtration test. With the NBD, the sand and gravel demand for the drain installation could be substantially relieved. The major conclusions are drawn as below:

(1) In terms of the expansive soil in this paper, the NBD is well-suitable for the seepage requirement under the condition of hydraulic gradient 1-4. On the premise of ensuring the structural stability of expansive soil, the adoption of NBD can not only ensure the drainage function, but also save part of sand.

(2) The equivalent opening size of the geotextile should be large enough within the design allowance, so that the floating soil particles can pass.

(3) The seepage was one-way constant in this paper, while the seepage fluctuates multi-directionally in actual cases, under the condition of which, the performances of the NBD should be further explored.

\section{Acknowledgements}

This work was supported by the National Key Research of China [2016YFC0401610], the Central Public-interest Scientific Institution Basal Research Fund of China [Y119001] [Y420005] and the Experimental Study on Performance Optimization of High Slope Seepage Drainage System in the Water Diversion Project from Yangtze River to Huaihe River [Hs120001].

\section{References}

1. Y. Lu, S. H. Liu, A. Eduardo, L. J. Wang, L. Xu, Z. Li. Volume changes and mechanical degradation of a compacted expansive soil under freeze-thaw cycles. Cold Reg. Sci. Technol. 157, 206-214 (2019)

2. F. Xu, Y. Cai, W. Qian et al. Mechanism of cemented soil modified by aliphatic ionic soil stabilizer. Chin. J. Geotech. Eng. 41, 9, 1679-1687 (2019)

3. Q. H. Wu, J. F. Zhang, J. B. Wu, X. Y. Liu. Physical model tests on slopes with control of infiltration by unsaturated drainage structures. Chin. J. Geotech. Eng. 39, 1, 154-160 (2017)

4. L. J. Wu, F. S. Wu, Y. Q. Liu et al. Research on material performance indexes for plastic blind drains. J. Hohai Univ., Nat. Sci. 31, 3, 264-267 (2003)

5. F. Xu, H. Wei, W. Qian et al. Experimental investigation on replacing cement by sintered limestone ash from the steelmaking industry for cement-stabilized soil: Engineering performances and micro-scale analysis. Constr. Build. Mater. 235, 117425 (2020)

6. J. L. Sherard, L. P. Dunnigan, J. R. Talbot. Basic properties of sand and gravel filters. J. Geotech. Engng. ASCE. 110, 6, 684-700 (1984)

7. J. Liu, D. S. Xie. Design principles and guidelines of filters. Rock Soil Mech. 39, 4 (2017)

8. L. Chen, Y. F. Zhuang, Q. Xu et al. Test study on filtration mechanism of silt-net system under limit soil-retained state. Rock Soil Mech. 29, 6, 14551460 (2006) 